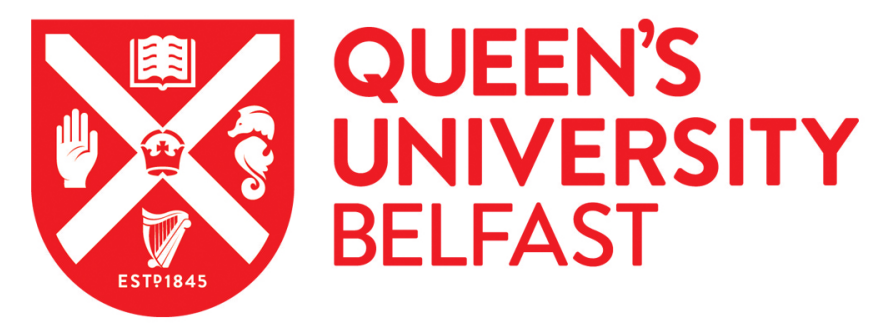

\title{
Doing Relationships and Sexuality Education with Young People in State Care
}

Hyde, A., Fullerton, D., McKeown, C., Lohan, M., Dunne, L., \& MacDonald, G. (2017). Doing Relationships and Sexuality Education with Young People in State Care. Health Education Journal, 76(2), 194-205. https://doi.org/10.1177/0017896916655181

Published in:

Health Education Journal

Document Version:

Peer reviewed version

Queen's University Belfast - Research Portal:

Link to publication record in Queen's University Belfast Research Portal

Publisher rights

(C) The Author(s) 2016

\section{General rights}

Copyright for the publications made accessible via the Queen's University Belfast Research Portal is retained by the author(s) and / or other copyright owners and it is a condition of accessing these publications that users recognise and abide by the legal requirements associated with these rights.

Take down policy

The Research Portal is Queen's institutional repository that provides access to Queen's research output. Every effort has been made to ensure that content in the Research Portal does not infringe any person's rights, or applicable UK laws. If you discover content in the Research Portal that you believe breaches copyright or violates any law, please contact openaccess@qub.ac.uk. 


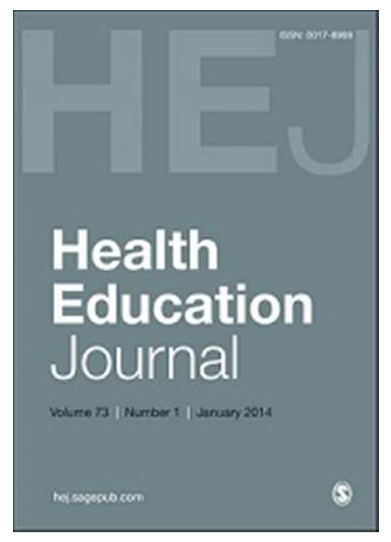

\section{DOING RELATIONSHIPS AND SEXUALITY EDUCATION WITH YOUNG PEOPLE IN STATE CARE}

\begin{tabular}{|c|l|}
\hline Journal: & Health Education Journal \\
\hline Manuscript ID & HEJ-15-0260.R3 \\
\hline Manuscript Type: & Original Article \\
\hline Keywords: & $\begin{array}{l}\text { sex education, looked-after young people, qualiative research, Ireland, } \\
\text { state care }\end{array}$ \\
\hline & $\begin{array}{l}\text { Abstract } \\
\text { Background: Existing literature indicates that young people in state care } \\
\text { have particular sexual health needs that include addressing their social and } \\
\text { emotional well-being, yet little has been published as to how these } \\
\text { components of sex education are actually delivered by service-providers. } \\
\text { Objective: To analyse the processes involved in delivering relationship and } \\
\text { sexuality education to young people in state care from the perspectives of } \\
\text { a sample of service-providers with a role in sexual health care delivery. } \\
\text { Design: Qualitative methodological strategy. } \\
\text { Setting: Service-delivery sites at urban and rural locations in Ireland. } \\
\text { Method: Twenty-two service-providers were interviewed in depth, and data } \\
\text { were analysed using a qualitative analytical strategy resembling modified } \\
\text { analytical induction. } \\
\text { Findings: Participants proffered their perceptions and examples of their } \\
\text { practices of sex education in relation to the following themes: (1) } \\
\text { acknowledging the multi-dimensional nature of sexual health in the case of } \\
\text { young people in care; (2) personal and emotional development education } \\
\text { to address poor self-esteem, emotional disconnectedness and an inability } \\
\text { to recognise and express emotions; (3) social skills' education as part of a } \\
\text { repertoire of compencencies needed to negotiate relationships and safer sex; } \\
\text { (4) the application of positive social skills embedded in everyday social } \\
\text { situations; and (5) factual sexuality education. } \\
\text { Conclusion: Insights into service providers' perceptions of the multi- } \\
\text { dimensional nature of the sexual health needs of young people in state } \\
\text { care, and the ways in which these service-providers justified their practice } \\
\text { make visible the complex character of sex education and the degree of skill } \\
\text { required to deliver it to those in state care. }\end{array}$ \\
\hline
\end{tabular}




1
2
3
4
5
6
7
8
9
10
11
12
13
14
15
16
17
18
19
20
21
22
23
24
25
26
27
28
29
30
31
32
33
34
35
36
37
38
39
40
41
42
43
44
59
45
46
47
48
49
50
51
52
54
56

SCHOLARONE ${ }^{m}$ Manuscripts

21

23

24

26

27

29

30

33

34

36

37

38

39

40

41

43

44

46

47

48

50

51

52

54

55

57

58

60

http://mc.manuscriptcentral.com/HEJ 


\title{
Doing Relationships and Sexuality Education with Young People in State Care
}

Abbey Hyde ${ }^{a}$, Deirdre Fullerton ${ }^{b}$, Caroline McKeown ${ }^{a}$, Maria Lohan $^{c}$, Laura Dunne ${ }^{c}$ and Geraldine Macdonald ${ }^{d}$

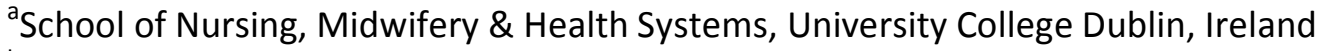

${ }^{b}$ Insights Health and Social Research, Derry, Northern Ireland

'School of Nursing \& Midwifery, Queen's University Belfast, Northern Ireland, UK

${ }^{\mathrm{d}}$ School for Policy Studies, University of Bristol, UK

\begin{abstract}
Background: Existing literature indicates that young people in state care have particular sexual health needs that include addressing their social and emotional well-being, yet little has been published as to how these components of sex education are actually delivered by service-providers.

Objective: To analyse the processes involved in delivering relationship and sexuality education to young people in state care from the perspectives of a sample of serviceproviders with a role in sexual health care delivery.

Design: Qualitative methodological strategy.

Setting: Service-delivery sites at urban and rural locations in Ireland.

Method: Twenty-two service-providers were interviewed in depth, and data were analysed using a qualitative analytical strategy resembling modified analytical induction. Findings: Participants proffered their perceptions and examples of their practices of sex education in relation to the following themes: (1) acknowledging the multi-dimensional nature of sexual health in the case of young people in care; (2) personal and emotional development education to address poor self-esteem, emotional disconnectedness and an inability to recognise and express emotions; (3) social skills' education as part of a repertoire of competencies needed to negotiate relationships and safer sex; (4) the application of positive social skills embedded in everyday social situations; and (5) factual sexuality education.

Conclusion: Insights into service providers' perceptions of the multi-dimensional nature of the sexual health needs of young people in state care, and the ways in which these service-providers justified their practice make visible the complex character of sex education and the degree of skill required to deliver it to those in state care.
\end{abstract}

Keywords: sex education, looked-after young people, Ireland, state care

\section{Corresponding author:}

Abbey Hyde, University College Dublin, B324 UCD Health Sciences Centre, Stillorgan Road, Belfield, Dublin 4, Ireland.

Email: abbey.hyde@ucd.ie 


\section{Introduction}

In Western countries, young people with a history of being in state care present health educators with particular challenges in light of their higher tendency compared to other young people of experiencing an earlier sexual debut, an early pregnancy and of contracting a sexually transmitted infection (STI) (Crocker \& Carlin 2002; Boonstra 2011; Dworsky \& Courtney 2010). Crocker and Carlin's (2002) UK study found that $77 \%$ of women with a history of having been in care reported having had first sex below 16 years of age compared with $35 \%$ of other women. With regard to teenage pregnancy, data also from the UK indicate that teenage girls in care are two-and-a half times more likely to become pregnant than their counterparts not in state care (Social Care Institute for Excellence 2004). In the USA, young adults with a care history are estimated to have between 3 and 14 times the risk of having an STI compared with young adults generally (Ahrens et al 2010). The increased vulnerability of young people in state care to sexual health difficulties is associated with the context of their lives including experiences of multiple placements, transient relationships with carers and limited contact with their families that may lead them to seek affection from sexual encounters (Crocker \& Scott 2006, Billings et al 2007, Dale 2009).

In this paper, we report on an aspect of a programme of research entitled the SENYPIC (Sexual Health and Sexuality Education Needs of Young People in Care) study, the most comprehensive study on the sexual health needs of young people in state care conducted in a European context (Hyde et al. 2016a, 2016b, 2016c, 2016d, 2016e), focusing on how service-providers reportedly delivered sex education to this cohort of young people.

In terms of what is known already about service-provider delivery of sex education to young people in state care, a limited amount of research has been conducted on the topic in the UK (Chase et al. 2006, Knight et al. 2006) and the USA (Constantine et al. 2009; Dworsky and Dasgupta 2014). The UK research (Chase et al. 2006, Knight et al. 2006) was a Department of Health-funded study on teenage pregnancy among young people in and leaving care and was based on interviews with 78 service providers whose role brought them in contact with young people in care. The purpose of the interviews was to investigate the experiences, roles and responsibilities of these professionals in preventing pregnancy and supporting young people in state care and young care leavers who were parenting. Findings revealed that participants identified the need for integrated responsibility among professionals and families for ensuring positive sexual health outcomes and support for the young people involved. Participants cautioned that responsibility may become diffused and diluted and the needs of young people may be overlooked. The need for clarity in the corporate parent role in addressing the emotional as well as practical needs of the young people was noted (Knight et al. 2006). In addition, the importance of consistency in the sexual health message imparted was emphasised by some professionals.

The US research on the topic reported by Constantine et al. (2009) aimed to assess the need for and the provision of sex education and reproductive health services among young people in foster care and those leaving care in three California counties. Included among the sample were 94 professionals providing services to these young people. A key finding emerging from these data was that addressing STI and pregnancy prevention at a surface level was insufficient as the context of young people's lives also needed to be considered. Similar to concerns raised in the UK study referred to above (Chase et al. 2006, Knight et al. 2006), division of responsibility across a range of professionals was a perceived challenge, and individual support from a caring adult was deemed to be important. 
Additional barriers to sexual health care provision included a lack of training in adolescent sexuality and diverse religious and moral beliefs that impacted on sexual health messages. A more recent US study in Illinois, that evaluated a training programme on sexual health with care givers and child welfare workers engaging with young people in state care, found that even after exposure to a training course, of the 218 respondents, $16 \%$ indicated that they could not put their 'personal values aside when talking with youth about sex health' (Dworsky and Dasgupta 2014, p.25). In keeping with other research cited above, the vast majority of respondents in that study acknowledged the impact of the context of their lives on the sexual health of young people in state care with almost $95 \%$ affirming that childhood trauma could affect their decisions about relationships.

While these studies have clearly found a belief among service-providers that young people in state care have particular emotional and social needs beyond sex-focused education, a detailed analysis as to how professionals deliver relationships and sexuality education (RSE) to these young people has not been located. In this paper, we attempt to contribute to a more refined understanding of the processes involved in delivering sex education to young people in state care by unpacking the perspectives and experiences of a sample of service-providers in Ireland on doing RSE and promoting sexual health among this cohort of young people. In analysing their reflections on their experiences of delivering RSE, we also consider their rationale for why they deliver it in the way that they reportedly do.

\section{Method}

Ethical approval for the study was obtained through the Human Research Ethics Committee at University College Dublin, the university leading the programme of research. A qualitative methodology was used for the component of the SENYPIC study being reported here.

The sample included 22 service providers in Ireland whose work brought them into regular contact with young people in state care. These were recruited through an earlier phase of the SENYPIC research programme during which 182 professionals responded to a survey of their perspectives on the RSE needs of young people in state care (Fullerton et al., 2016). Survey respondents were asked to indicate if they would be willing to take part in an in-depth interview on the topic and 92 agreed. However, as this would be an unwieldy number of participants to interview, it was decided to select participants purposefully for the interviews with priority given to those working directly with young people in state care or in the area of sexual health training of care staff. Information on the degree of contact daily, weekly or monthly - and the precise nature of their role had been captured via the survey instrument. In addition to their professional involvement with young people in state care, selection was influenced by the need to include those from a variety of professional roles so that a rich and comprehensive picture from a range of vantage points would emerge. Some providers had experiences of service delivery to young people in both foster care and residential settings, while others had worked in one of these settings at different points in their career. As interviews progressed, it became clear after 22 interviews that no new issues were emerging (data saturation had been achieved) and this was the ultimate sample size. While no deliberate effort was made to recruit on the basis of gender, of the 22 participants ultimately interviewed, seventeen were female and five male. This gender breakdown reflects the preponderance of women working in service-provision with young 
people in state care. All participants had at least three years' of experience in either health or social care. The age range of the young service users whom the service-providers encountered tended to vary. Pseudonyms have been used for all participants throughout to protect their identities.

Participants were engaged in both direct service-provision (delivering the sex education and sexual healthcare) and indirect provision (such as training staff in the area of sexual health or in supervising those providing direct care to young people). Participants were drawn from the following professional areas: social work, social care, counselling, outreach services, health promotion, nursing, youth work, health work and education. These professionals worked in a variety of locations, both rural and urban, throughout Ireland.

In advance of the interview, each participant received an information sheet with details of the study. Nineteen of the interviews were conducted by telephone and three were conducted face-to-face). Interviews were audio-recorded and subsequently transcribed. Reflecting the aim of the wider SENYPIC study, interviews were structured around a topic guide designed to capture what participants perceived to be the sexual health needs of young people in state care. It was in the course of teasing out participants' perspectives on the sexual health needs of young people in state care that rich data emerged on how they reportedly delivered RSE to this group and how they justified their practice of RSE. Most interviews lasted one hour approximately but ranged from $\mathbf{3 0}$ minutes to 1.5 hours.

The strategy for analysis followed closely that advanced by Bogdan and Biklen (2007) referred to as modified analytical induction (MAI). This involves comparing whole transcripts with other whole transcripts to fill out the bigger picture as opposed to cutting and slicing data segments as happens in other qualitative analytical strategies. In the case of the current study, the process of analysis was as follows: the first transcript was paraphrased with particularly telling quotations preserved verbatim. This provided a relatively holistic view of that participants' account. Further transcripts of other participants were folded in to the initial (paraphrased) narrative in the same way with patterns and indeed different or new findings accommodated into the expanding account. This process continued until all transcripts had been incorporated into the whole picture. The early interpretation of data became more refined as the analysis progressed. Later interviews were found to contribute little to the emerging whole narrative as data saturation was reached. The strategy was useful to ensuring that the strength of particular themes could be identified based on how dominant they featured across interviews, and no aspects of data were excluded from the overall analysis. It also ensured the trustworthiness of data, with the strongest claims supported by the strongest empirical evidence in the form of raw data.

\section{Findings}

The perspectives and experiences of participants in delivering RSE and promoting sexual health for young people in state care are captured around five themes, namely: (1) the multi-dimensional nature of the sexual health needs of young people in care; (2) personal and emotional development education; (3) social skills' education; (4) the application of social and emotional skills in everyday life; and (5) factual sexuality education. 


\section{The multi-dimensional nature of the sexual health needs of young people in care}

A range of factors were identified as being important to meeting the sexual health needs of young people in state care, and participants highlighted practices and techniques that they used in their everyday work or that they believed constituted good practice. Among these factors were a positive and meaningful relationship between professional and young person, sound knowledge and a confidence to deliver this, and a non-judgemental approach.

A number of participants referred to the myriad of sexual health needs of young people in state care in terms of 'pieces', reflecting the multi-dimensional nature of sexuality. The need for a holistic approach was illustrated in the following quotation, where the range of components of sexuality education normatively expected to be met within the family environment is identified.

Well again, like that, I suppose when they are in care it is like you are in loco parentis and so in that sense if you are looking at it from the family dynamic. It is providing them with all of the education of the academic piece, the skills' piece but also just the human development piece about who they are and what they are and where they are going. (Aimee, female, sexual health trainer of professionals)

Another participant (Eiblín, female, sexual health trainer of professionals), described the needs of young people in state care with the analogy of a 'jigsaw'. She noted that service-providers whom she encountered frequently needed support themselves to understand how to integrate 'the pieces of the jigsaw' that went beyond the bio-scientific dimensions of sexuality. The holistic approach was otherwise described as a layered process', involving programmes that started with 'self-esteem, self-confidence and selfawareness', with sexuality and sex education 'worked in' (Jackie, female, social worker). Another, Julia (female, teen-parent support worker), described this as 'tiered' noting that with respect to young people with a relatively stable upbringing, providing factual and scientific information would be acceptable since these teenagers experience normative stable relations played out in their everyday lives through which to process information. For young people in state care, however, she contended that 'sexual health work needs to be more therapeutic and thought out'.

While emotional and social aspects of relationships and sexual health education are heavily intertwined, they are explored separately below in order to understand them more clearly.

\section{Personal and emotional development education}

A dominant theme across the interviews was the centrality of emotional issues that young people in state care tend to have, though the degree of emotional need was deemed to vary depending on the young person's background. The problems of poor self-esteem, emotional disconnectedness and inability to recognise and express emotions among young people in state care were a recurring theme. The problems identified by service-providers here 
strongly reflect those identified in international literature on the mental health of young people in state care (McAuley and Davis 2009).

Alicia (female social care worker) described the emotional learning that occurs in emotionally healthy and stable contexts as happening covertly and though unconscious approval and disapproval, a phenomenon well established within socialisation theory (Handel et al. 2007). However, those with a history of childhood trauma, she noted, 'have been denied that "natural" opportunity to learn these things'. Hence, Alicia perceived formally teaching emotional consciousness as part of her role. Other participants also spoke of the need to facilitate those who had experienced emotional deprivation to connect with a spectrum of human emotions. They also noted that emotional expression among those who had experienced emotional instability tended to be confined to anger or aggression.

A whole nurturing factor as well; a lot of them [in care] would be deprived of that from a very young age. Instability can cause them to be aggressive and that . . . is all they know how to express themselves a lot of the time. (Georgina, female, currently aftercare worker, previously residential care worker)

Participants who delivered sexuality education described the process of selfawareness education that is required to enable young people to identify a range of emotions, so that these may be expressed in a safe environment, without the threat of negative responses from those in authority.

While a non-judgemental disposition in sexuality education was generally advocated by participants, they reported that there were times when that the educator needed to take an ethical stance. Enabling a young person to become emotionally sensitive to behaviours considered by the educator to be unethical required the educator to take a clear position and to convey this in a transparent way to the young person. This ability to discriminate appropriate from inappropriate behaviour was considered to be an important part of a young person's emotional development.

You need to have a value system that says when is something not okay. It's not okay to say to young person, 'It's okay for a 13-year-old to have sex with a 19year-old.' (Regina, female, advocacy worker)

Now there are some things you don't want to be neutral on: You don't want to be neutral on abuse, you don't want to be neutral on things that ultimately would give the young person the wrong message. So you are not going to be neutral on rape, you are not going to be neutral on abuse, those kind of things. (Eiblín, female, sexual health trainer of professionals).

Norma (female, residential care psychologist) reported that part of her educational role was to help young people understand the characteristics of an abusive relationship, what emotions might mediate it and what an egalitarian relationship should feel like. She did this through consciousness-raising activities with young men. Understanding that one should choose to have sex when one was emotionally ready rather than drift into sexual relationships was the key, according to Megan (female, social care worker), as was 
equipping young people with the social skills to engage in sexual activity safely if they so chose.

The issue of embedding elements of 'formal' emotional and social skills' learning into everyday life will be considered further on.

\section{Social skills' education}

One part of the 'jigsaw', and something that was reportedly transmitted in a deliberate formal way as well as reinforced through everyday interaction in the social care environment (that we consider later), was a range of social skills as follows:

Skills in making decisions, skills in being assertive, skills in being able to take 'No' for an answer. Those kind of basic skills for negotiating with other people are really essential. (Eiblín, female, sexual health trainer of professionals)

Other skills referred to by interviewees were those of listening, asking questions and seeking clarification. These skills are critical in maintaining mutually respectful relations and in negotiating safer sex - conveying consent to sexual advances or signalling sexual boundaries. Indeed, the skills to manage consent were referred to by several participants engaged in front-line RSE. One of these, Norma (female, residential care psychologist) working in a residential centre, described alerting boys to the complexities around consent and the grey area that may arise around interpretations of rape.

We do a lot around the question of consent and I think they are quite shocked of how easily they could be accused of rape. And that does make them sit up and take notice. Consent is much more complex - how do you know how far to go? Do you stop and ask her every so often? How can you be sure that she is willing to do this? These are the issues to be teased out. (Norma, female, residential care psychologist).

The reference to asking 'her' about issues of consent suggests a hetero-normative stance on the part of the educator. However, it should be noted that when asked about LGBT identities, participants across the sample expressed an openness to engaging with these when considering the sexual health needs of young people in state care.

Aimee (female, sexual health trainer of professionals) also spoke of her attempts to convey the notion that consent is far from straightforward. She noted that its complexity is intensified because the social cues in an environment of abuse and emotional disconnectedness are different from those in a more normative context.

We would look right down to the basics: How do you know if somebody is consenting, what are the signs that they are consenting and how would you know if somebody consented but then changed their mind? What are the signals? And again it might seem like a very basic thing but for a lot of young people who have been brought up in difficult environments, that message would have passed them by. And young people who have been sexually abused would be totally confused about that message. (Aimee, female, sexual health trainer of professionals) 
Very often a young person who has got low self-esteem or who is struggling in any way, they might feel 'I can't ask a question because they will think I am stupid,' or 'I am 16 so I have to pretend I know that.' So it is about teaching young people that actually, learning is all about asking questions; there is no such thing as a stupid question and we model that on an ongoing basis. (Eiblín, female, sexual health trainer of professionals)

What care workers appear to be doing in deliberate yet subtle ways is weaving good communication skills into their everyday interactions with young people. This promotion of social skills' learning by immersion and modelling is supported within scholarship on social learning theory (Bandura 1977). As Aimee (female, sexual health trainer of professionals) describes this, the unconscious learning of mutually respectful normative rituals of interaction mediates sexuality education (in its broadest sense) in stable family environments through unconscious learning. Without this unconscious learning, she contended, 'school based' (or formal) sexuality education is insufficient.

So much of the sexual health needs of children in more stable families are met without them even knowing that they are doing sexuality health. Just in the way they relate to each other and the positive affirmation that kids might get, you know, all those bits that build up their self-esteem and their image of themselves, the man or woman, you know all that piece that happens in more stable families. And if that is not happening for those young people who are already disadvantaged, who already have experienced huge gaps in their development in terms of who they are and how valuable they are and what a healthy relationship 
is, what they can expect and what they should be able to demand in terms of respect and just acceptance and value of themselves. If that is not there then the stuff in school is not enough. (Aimee, female, sexual health trainer of professionals)

The application of emotional awareness learning was also articulated by Crona (female teen-parent support worker) who described the importance of simply making the young person in care aware that someone else is engaged in sharing with them their thoughts and emotions.

If the child feels thought about, they are experiencing something, they are experiencing being thought about and that can happen in the most simple way or complex. Even showing interest, it's also important to wonder with the child, to ask with the child. Let's make it explicit that we are holding them in our minds. (Crona, female teen parent support worker)

Connor (male, social worker) described the process of embedding social and emotional learning in everyday life as 'giving them some sort of normality or some kind of sense of what is normal and what is okay.' Interactions in residential centres, according to Loretta (female, social care worker), should create an environment in which 'people negotiate with one another how they make decisions together' suggesting that decisions are usually made for young people in residential care without sufficiently involving the residents. Margaret (female, aftercare worker with considerable previous residential experience) similarly promoted role modelling by staff as a social learning strategy, noting that, 'They [those with emotional issues] don't know how to be nice or affectionate towards people. And working on the staff team it's up to us to show by example'.

Yet even if civility and courteousness through interactions were displayed by staff, an obstacle to a young person in residential care practising social and emotional skills was the reluctance of some care staff 'to reveal their own lives and relationships.' As Regina, (female, advocacy worker) observed, the relationship was blatantly hierarchal, insofar as staff were privy to a considerable amount of information about that young person (for a detailed analysis of this see Hyde et al. 2016e) but the exchange of personal knowledge was not reciprocal. She noted that the relationships that the young people see played out in residential care were not 'real' relationships, but are professional relationships that are very guarded. This impacts on the young person being 'held' emotionally and physically in a reciprocal way, she observed, and drives them to seek 'intimacy and sex as a means of having a close connection, rather than have that sterile environment that you get in residential care'. One means for addressing the inherently hierarchical nature of relationships between young people and staff proposed by Gerard (male, outreach programme worker) was to have those leaving care or in aftercare mentored by older peers who had formerly been in care and who had shaped their lives positively after leaving care.

It is worth noting the reservations of two participants who raised issues about the extent to which young people were allowed to develop (or practise) their social skills within residential settings. The first, Olive (female, psychologist on a multi-disciplinary team), conveyed the view (based on clients of hers from care settings) that relations between care 
staff and service-users were excessively authoritarian, with insufficient emphasis on negotiation.

They tend to be ruled by the rules a bit too much. I think that there should be more flexibility. I think the behavioural management piece can be a little harsh. I know resources are tight, but there is a lot of emphasis on control rather than discipline. They need to be able to make decisions. Even in the most stable backgrounds there are meltdowns. Young people need to be listened to, and there needs to be more counselling skills into training for social care people. . . it needs to be collaborative rather than dictatorial. (Olive, female, psychologist)

Norma, also a psychologist, lamented that being in residential care meant that young people had limited opportunity to try out new techniques for negotiating relationships to which they were introduced during her group work. Although she acknowledged the positive efforts of residential care staff in embedding social skills into everyday encounters, some of the feedback that she received from service-users indicated that there were areas for improvement.

I hope a lot of it [the social skills piece that she teaches] is apparent in their dayto-day work within care: seeing and experiencing positive relationships, seeing different ways in which adults deal with young people, therapeutically in the living environment. I think it has to be done in residential care across the entire setting to give them opportunities to be positively assertive ... when dealing with staff they will often say 'But there is no point, what's the point in trying to argue my case or raising this particular grievance because it doesn't get anywhere,' or 'We'll just be labelled as argumentative', so we are trying to give them experience in this setting of managing themselves. (Norma, female, psychologist residential care)

\section{Factual sexuality education}

Although a minority of participants regarded the RSE needs of young people in state care to be no different from their peers not in care as far as biological (i.e. reproduction and safer sex) and other factual (i.e. legal issues, sexual health services, etc) information was concerned, most contended that young people in state care had additional needs in this regard. In view of the tendency for young people in state care to have complex needs (e.g. attention difficulties), the capacity of some of them to process the information was raised. Olive (female, psychologist) observed that some fairly basic biological information '[goes] right over their heads' and the level of detail needed to be modified accordingly. This would appear to be important in light of Dale's $(2009$, p.30) finding of a gap between the formal knowledge of health professionals and the 'everyday ways of speaking' of service-users in her study of ten young people in state care in Scotland.

Eleanor (female, service manager) indicated that assessing exposure to prior knowledge was important in delivering factual sexuality education and informed the decision as to what content to deliver. 
I think again it depends on what stage they have come into care and what they have already learned. I mean the other thing is whether they have had any sex education before and what that has been. If it has just been the fifth class talk or the sixth class talk, that is going to be very different from somebody who has had some education all the way through or a young person who has been in care where there has been ongoing development of their sexual needs or assessing their sexual needs than somebody who has come in at 14 who has never been told anything. (Eleanor, female, service manager)

A few participants suggested that while young people (including those in care) may give the impression that they are well-informed about the scientific facts about sex, this was not always the case. Young people may have missed out on this teaching at school, may not have attended to the lesson, or may have been exposed to misinformation through friends. One proposed approach to teaching was to acknowledge that young people may have information already and hence affirm their prior knowledge but not assume this. The sensitivity required to engage young people is captured by the following quotation:

But again you have to be very careful in how you present it. So we would say to young people, rather than something that isolates them or alienates them, like we would never say, 'We are going to do the basics with you'; We would say, 'You probably know all this already but let's just do a recap.' And that way then we're giving them permission to sit there and they don't have to feel insulted, they don't have to feel embarrassed if they don't know stuff. . . I would say certainly we would start with the biological. (Aimee, female, sexual health trainer).

The above examples illuminate how a practice ordinarily constructed as perfunctory (conveying biological 'facts') actually demands a highly skilled approach. A few participants referred to the need for the educator to tailor the level and substance of the educational materials to the needs of the learner, based on his or her past experiences.

You could be talking about children who have been abused or may have abused themselves, so knowing your client is very relevant. (Georgina, female, currently aftercare worker, previously residential care worker)

For some young people in care they may not have had the parental supervision that would have protected them from early sexual experiences. So my view would always be if they have had sexual experiences or if they plan on continuing to be sexually active you need to give them a level of information that matches their past or current experiences. (Eiblín, female, sexual health trainer of professionals)

While age-appropriateness was mentioned as a factor that mediated the factual content of sexuality education, it was not the only guiding factor in delivering sexuality 
education. Educators were also challenged to attune their educational endeavours by discriminating within an age cohort. This required the careful appraisal of environmental and contextual factors.

So what you might think wholly inappropriate for a 13-year-old brought up in a protective loving caring environment might actually be crucial for the well being and safety of another 13-year-old in residential care who didn't have that kind of safety and security in their lives... . even within residential care the information we would give to one 13- or 14-year-old might not necessarily be what another needs. (Eiblín, female, sexual health trainer of professionals)

In terms of the content of biological information, a participant working in aftercare stressed the need for more education around STIs, as in her experience, care leavers tend to 'bury their head in the sands' about the dangers to which they exposed themselves.

\section{Summary and conclusion}

In teasing out these service-providers' educational practices, teaching strategies, and perspectives, participants' sense of the multi-dimensional nature of the sexual health needs of young people in state care becomes clear, including the need to learn social and emotional skills and to apply these to everyday life. The perceived need for factual sexuality education for young people in state care was also evident. These findings contribute to knowledge in the field by providing an in-depth empirical account of reported RSE practices with young people in state care that goes beyond the accounts currently published in existing literature (Chase et al. 2006, Knight et al. 2006, Constantine et al. 2009)

A dominant theme expressed by participants in this study was that for many young people in state care, their background is characterised by exposure to violence and/or unequal relationships, requiring re-socialising and modes of interaction that privilege dignity and respect over dysfunctional notions of 'normal'. While re-learning mutuality in relations has relevance across their social milieu, it carries over to healthy sexual relations. This type of 'teaching', that might be described as semi-formal, is far less visible and tangible than more formal learning, yet it may have the greatest impact judging by the heavy references to deficits in mutuality and value-orientation in the prior relations of many young people in state care (acknowledged in participants' accounts and in academic literature). It is also possibly the most difficult type of teaching to evaluate using well-established pre- and postintervention measures that dominate social science scholarship because it does not constitute a discrete 'intervention' amenable to measurement. Data presented here also suggest that in some care settings, this type of embedded social learning may need to be strengthened.

In analysing participants' reports of their RSE practices, we are not claiming that these necessarily amount to 'good practice' since good practice is a negotiated status, socially produced and subject to historical and cultural shifts in contemporary health education discourses. Determining what constitutes good practice requires a value judgement and whether a practice is good or bad may depend on the subtle dynamics of the situation. Rather, the foregoing analysis illuminates how service-providers reportedly 
practised and justified their decisions and actions with reference to providing RSE to young people in state care. Based on those reports RSE delivery appeared to be rooted in well thought-through practices. These practices may be used by as a basis for discussion in the teaching of RSE practitioners going forward.

A limitation of the study is that data were only collect from professionals in one country. Findings may have been very different if interviews had been conducted in other countries with different norms and different state care contexts. Another limitation is of course that data were gathered through self-report, and the version presented by participants at interview may well be an idealised account of how they might like to deliver RSE. Notwithstanding this possibility, we argue that it is important that the finer details of sexual health work are captured in order to acknowledge the potential contribution of those delivering this and to make visible the sometimes taken-for-granted yet apparently highly skilled work that sexuality education to a cohort of young people with specific challenges involves. Those who train professionals to deliver RSE might consider including in their programmes the kind of semi-formal strategies used by participants in this study. Workplaces might also consider formally encouraging day-to-day practices that facilitate all staff dealing with young people to embed broader RSE in everyday encounters.

\section{Acknowledgement}

The authors would like to thank the Health Service Executive Crisis Pregnancy Programme for funding this study. The opinions expressed in this publication are of the researchers and are not necessarily those of the sponsor.

There is no potential conflict of interest, real or perceived. The study was sponsored by the Health Service Executive that receives its funding entirely from the Irish government. The study design was developed by the research team and approved by the sponsor. A Steering Group of national experts in child protection, sexual health and child health offered guidance and advice throughout the study but had no role in the collection, analysis, and interpretation of data, nor in producing the manuscript. The first draft of the article was written by Abbey Hyde and no honorarium, grant, or other form of payment was given to anyone to produce the manuscript.

\section{Note}

These data and sections of text appear in reports submitted to the funding body on completion of the study. 
References

Ahrens KR, Richardson LP, Courtney ME, et al. (2010) Laboratory-diagnosed sexually transmitted infections in former foster youth compared with peers. Pediatrics 126: e97e103.

Bandura, A (1977) Social Learning Theory. Englewood Cliffs, NJ: Prentice Hall.

Billings, J, Hashem, F and Macvarish, J (2007) Looked-After Children's Views of Sex and Relationships Education and Sexual Health Services. Kent: Centre for Health Services Studies, University of Kent.

Bogdan, R and Biklen, S (2007) Qualitative Research for Education ( $5^{\text {th }}$ Edition). New York: Pearson International.

Boonstra, H (2011). Teen pregnancy among young women in foster care: A primer. Guttmacher Policy Review 14: 8-19.

Chase, E, Maxwell, C, Knight, A, \& Aggleton, P (2006) Pregnancy and Parenthood among young people in and leaving care: What are the influencing factors and what makes a difference in providing support? Journal of Adolescence 29: 437-51.

Constantine WL, Jerman P, Constantine NA (2009) Sex Education and Reproductive Health Needs of Foster and Transitioning Youth in Three California Counties Oakland, California: Center for Research on Adolescent Health and Development, Public Health Institute.

Crocker, AR and Arlin, EM (2002) Coitarche and care: Does experience of the 'looked after' system affect timing of a woman's sexual debut? International Journal of STD and AIDS 13: 812-814.

Crocker, C and Scott, S (2006) "Improving the mental and emotional well-being of looked after children: connecting research, policy and practice." The Journal of the Royal Society for the Promotion of Health 126(1): 18-23.

Dale, H (2009) The Sexual Health Needs of Looked After Young People. Scotland: NHS Fife.

Dworsky, A and Courtney, ME (2010). The risk of teenage pregnancy among transitioning foster youth: Implications for extending state care beyond age 18. Children and Youth Services Review 32: 1351-1356.

Dworsky, A, and Dasgupta, D (2014) Preventing pregnancy and promoting sexual health among youth in care: Results from the evaluation of a training for caregivers and child welfare workers. Chicago: Chapin Hall at the University of Chicago.

Fullerton D., Hyde A, McKeown C, Lohan M, Dunne L and Macdonald G. (2016) Sexual Health and Sexuality Education Needs Assessment of Young People in Care in Ireland (SENYPIC): A Survey of Service-provider Perspectives. Report No 1. Dublin: HSE Crisis Pregnancy Programme and Child \& Family Agency (Tusla).

Handel, G, Cahill, S and Elkin, F (2007) Children and Society: The Sociology of Children and Childhood Socialization. Oxford: Oxford University Press.

Hyde A, Fullerton D, McKeown C, Dunne L, Lohan M, and Macdonald G. (2016a) Sexual Health and Sexuality Education Needs Assessment of Young People in Care in Ireland (SENYPIC): The Perspectives of Key Service-Providers: A Qualitative Analysis. Report No 3. Dublin: HSE Crisis Pregnancy Programme and Child \& Family Agency (Tusla).

Hyde A, Fullerton D, Dunne L, Lohan M, and Macdonald G. (2016b) Sexual Health and Sexuality Education Needs Assessment of Young People in Care in Ireland (SENYPIC). The Perspectives of Care Leavers: A Qualitative Analysis. Report No 5. Dublin: HSE Crisis Pregnancy Programme and Child \& Family Agency (Tusla). 
Hyde A, Fullerton D, Lohan M, , McKeown C, Dunne L, and Macdonald G (2016c) Sexual Health and Sexuality Education Needs Assessment of Young People in Care in Ireland (SENyoung people in state care): Composite Report of Findings. Report No 6. Dublin: HSE Crisis Pregnancy Programme and Child \& Family Agency (Tusla).

Hyde A, Fullerton D, Lohan M, Dunne L, and Macdonald G (2016d) The role of knowledge in the contraceptive behaviour of sexually active young people in state care. Sexual \& Reproductive Healthcare (8): 37-41.

Hyde A, Fullerton D, Lohan M, , McKeown C, Dunne L, and Macdonald G Howlin F \& Healy M. (2016e): The perceived impact of interprofessional information sharing on young people about their sexual healthcare. Journal of Interprofessional Care Available at: http://dx.doi.org/10.3109/13561820.2016.1154022.

Kitzinger, C and Frith, H (1999) Just say no? The use of conservation nalysis in developing a feminist perspective on sexual refusal. Discourse \& Society 10 (3): 293-316.

McAuley, C and Davis, T (2009) Emotional well-being and mental health of looked after children in England. Child \& Family Social 14 (2): 147-155.

Knight, A, Chase, E \& Aggleton, P (2006) Teenage pregnancy among young people in and leaving care: Messages and implications for foster care. Adoption and Fostering 30: 58-69.

Social Care Institute for Excellence (2004) Preventing teenage pregnancy in looked after children. Briefing 9. London: Social Care Institute for Excellence. 